\title{
Mindfulness, Authenticity and Participation.
}

\section{Josh Green}

Performing Arts Department, School of Arts, Digital and Creative Industries, Northampton College, Northampton, United Kingdom

\begin{tabular}{|c|c|}
\hline KEYWORDS & A B STRACT \\
\hline $\begin{array}{l}\text { Mindfulness } \\
\text { Authenticity } \\
\text { Participation } \\
\text { Liminality } \\
\text { Equanimity } \\
\text { Non-self } \\
\text { Impermanence } \\
\text { Uncertainty } \\
\text { Existentialism }\end{array}$ & $\begin{array}{l}\text { Participatory works by performance makers like Charlotte Spencer, Marina Abramović and An } \\
\text { Xiao do not explicitly cite Buddhist or existentialist traditions, yet they evoke impermanence and } \\
\text { the non-self, encourage equanimity, question facticity and embrace becoming. This paper } \\
\text { explores how and why attitudes of mindfulness and existential mechanisms of authenticity } \\
\text { become manifest in contemporary forms of participatory performance. It proposes that liminality } \\
\text { is central to the efficacy of these participatory modes of performance, as they attempt to engage } \\
\text { with the uncertainty participants face in modern life. }\end{array}$ \\
\hline
\end{tabular}

\section{Introduction}

Mindfulness (sati) can refer to a wide variety of strategies, practices, or mental states. It is a hybrid of a range of different Buddhist traditions and sits at the centre of a collection of meditative practices endeavouring to develop awareness, attention and compassion (Lalioti, 2019). I have been engaged in a practice of meditative mindfulness since December 2018. I was drawn towards mindfulness initially as a means of managing the anxiety I felt, triggered by the final stages of my doctoral studies and the uncertainty it presented. Once I had completed my PhD, I continued to meditate; I had successfully kept my anxiety at bay long enough to affix those all-important initials (Dr) before my name. But the more I meditated, the more confluences I recognised between the processes and attitudes of mindfulness, the existential philosophy of authenticity (an area I was already actively investigating), and contemporary manifestations of participatory performance - which I consider to 
be one of the more exciting and significant shifts to have happened (and is still happening) in the performing arts since the turn of the $21^{\text {st }}$ century.

Through my engagement with mindfulness, I have identified a number of concepts, attitudes and/or virtues which have come to shape my own first-hand understanding of it. A heightened and acute awareness of one's present experience (thoughts, sensations and emotions) above all else (past memories and future projections) cultivates an appreciation of the fundamental impermanence (aniccā) that permeates all things. This increased cognizance is then augmented by attitudes of nonidentification with one's experience, and non-judgement of, for example, one's capacity to focus on the present moment. This culminates in an acceptance of the fundamental 'non-self' (anattā). All of the above should be approached from a perspective of calmness and moderation in the face of a chaotic, uncertain and frenzied mind and lived experience: equanimity (upekkhal tatramajjhattata). Two of these three concepts (impermanence and non-self) constitute two of the three Buddhist 'marks of existence' (tilakkhana) identified in the Dhammapada'. Equanimity is also one of four 'sublime attitudes' (brahmavihārās), according to the Metta Sutta ii. Although Buddhist in origin, these attitudes have permeated secular meditation praxes and appear to be the central building blocks of the contemporary mindfulness movement.

I propose that some of the fundamental attitudes and concepts of mindfulness (specifically those mentioned above) and existential authenticity intersect in a number of significant ways. I hope that by identifying these different areas of confluence, mindfulness (and many of its associated attitudes and ideologies) can be considered a legitimate means of pursuing and realising (what western 
existential philosophy terms) authenticity. I will explore this framework through contemporary participatory performance practice, highlighting how it might be disseminating, exploring, questioning and/or employing these concepts and practices for audiences, perhaps without even realising it.

The main areas of convergence across mindfulness, authenticity and participatory performance centre around the concepts of impermanence, selfhood (or resistance to selfhood through the nonself) and equanimity. Each of these three points in the framework are in some way liminal: always in progress, never fixed in one position, fundamentally between states and categorically uncertain. Impermanence is predicated on the ceaseless shift from one state to another. When an understanding of impermanence is applied ontologically to one's understanding and constitution of the self, the flux of the non-self is defined as constantly being in-between states. If an attitude of equanimity is applied to one's experience, one cannot be said to truly be a part of any situation, but rather betwixt and in some way separate from it.

Lalioti (2019) posits that many performance-makers (both intentionally and unintentionally) generate a liminal state through their work. In doing so, they cultivate the conditions wherein audiences' beliefs, perceptions and identities can be temporarily suspended, inspected and potentially transformed. To the extent that liminal performance processes embrace the attitude of equanimity, the concept of the non-self and an awareness and acceptance of transience, they can be considered instances of 'shared mindfulness'. I propose that this liminality, and the attitudes of mindfulness that it facilitates, are both intensified and more prevalent in instances of participatory performance, including (but not limited to ${ }^{\mathrm{iii}}$ ) Charlotte Spencer's Is This a Waste Land? 
(2017), Marina Abramović's The Artist is Present (2010) and An Xaio's response piece, The Artist is Kinda Present (2010). I propose that these performances (and others like them) are in some way shaped by the growing culture of mindfulness. The artists do not explicitly cite Buddhism or existentialism in the work itself. But it is nonetheless permeated with concepts, attitudes and insights associated with mindfulness. If these ideas are common across both mindfulness and existentialism, the pursuit and/or problematisation of (what existentialists might consider) an authentic expression of the self (in the face of contemporary life) may also be explored in these performances as they evoke mindfulness.

\section{Impermanence}

In mindfulness praxis, a profound understanding and acceptance of impermanence (anicca) is integral not only to developing an attitude of non- identification towards one's thoughts, emotions and/or sensations, but also to approaching one's meditative practice (and life) from a non-judgemental perspective. The phrase 'this too shall pass' is emblematic of the constant state of transience that one is encouraged to acknowledge in mindfulness practice. By recognising the ephemerality of all thoughts, emotions, sensations, phenomena, and indeed one's very existence, one can surrender the desire to preserve some phenomena and to dispense with others.

This acute awareness of allencompassing transience appears consistently throughout western existential thought. Existentialism is the study of existence, but it has almost exclusively been investigated through the lens of human existence (MacQuarrie, 1972). In existentialism it is assumed that humans have the capacity to reflect on past acts and experiences, but also to project 
themselves into the future and contemplate different possibilities (Crowell, 2020). This is one of the unique qualities of human existence.

The concept of impermanence is already fundamental to the ephemerality of the live performance event (Kershaw, 2011), however participatory performances like Charlotte Spencer's Is this a Waste Land? (2017) drew particular attention to it. She did so in two ways. Firstly, the choreographer's site-specific performances were situated in the overgrown remains of demolished buildings. These sites rested dormant and unused, awaiting development by prospective building firms. Without the temporal facility to recall the past and speculate about the future (assumed by existential thought) Spencer's waste lands would not have held the same significance. Even the language I am compelled to use to describe it ('dormant', 'awaiting', 'prospective', etc.), is littered with terminology predicated on one's perception of time. Without the context of their past and potential future, the sites lose their specificity. The sites themselves were impermanent and Spencer herself was forced to be 'flexible, agile, adaptable, transient, moveable' (Spencer, 2017) as she found sites and inhabited them before they were purchased and built upon. The sites' impermanence was the very thing that gave them meaning for Spencer, and this meaning was in turn communicated to participants through their exploration of them.

Martin Heidegger famously called 'the distinctive mode of Being realized by human beings' (Wheeler, 2020) (or Dasein) a 'Being-towards-death' (1927). By doing so, Heidegger implies that acceptance of the fact of one's own finitude and inevitable death (and therefore transience) is the cornerstone of generating meaning in one's life and living authentically ${ }^{\mathrm{iv}}$. The meaning of one's life is in the acts one performs, whilst 
maintaining a full awareness that one day, one will no longer have the vitality or animation to act at all. By directing participants to act within and upon the temporarily empty sites, Spencer reinvigorated and re-animated the waste lands. These acts were given greater significance, not only by the ephemerality of the performative mode, but also by the implicit knowledge that the sites would shortly cease to exist as sites of performance; as waste lands.

The second way Spencer underscored uncertainty and impermanence was through the activities participants were asked to perform. Upon arrival, at one of Spencer's venues (empty urban sites awaiting development), participants were issued a set of wireless headphones, verbally directed (through a voice emanating from the headphones) to choose a piece of the industrial detritus scattered nearby, survey the area from multiple angles, and (depending on their assigned narrative) start construction. Walls and towers were built by participants (and incognito performers), but then destroyed without warning by others. The remains were rebuilt into something else again and again. The cycle was impermanence incarnate. Once it had happened enough times, the construction process was stripped of any ego and participants built with the explicit knowledge that their work would be annihilated. They built for the sake of the destruction; the bigger they were, the harder they fell.

Spencer has not explicitly cited mindfulness, nor any meditative practice in the creation of her work. Although it may not be her intention to evoke impermanence as a concept within a specifically meditative or remotely Buddhist context, Is this a Waste Land? has been described by participants as "both a mindfulness exercise and task-based immersive performance.' (Irvine, 2017) The 
piece was primarily concerned with the themes of 'commodification and privatisation of space [..] home and community [...] waste and capitalism [...] nourishment and taking care [and] living with uncertainty' (Crawford, 2016) This last theme in particular - alongside the problematisation of commodification as a process of inertia, but also wasteful consumption - gives some explanation as to why impermanence was featured so prominently. Instructing participants to build structures, only for them to be destroyed shortly after, was an unambiguous representation of the uncertainty and constant state of flux deeply ingrained in modern life. The repetition of this cycle of construction and destruction not only emphasised this point, but also celebrated it. When I participated in the performance, I was stunned and wounded the first time one of my structures was destroyed and/or dismantled; by the third time, I accepted and even excitedly anticipate its collapse. I had learned to detach myself from my endeavours and embrace the impermanence of the objects I had helped build and (in doing so) acknowledge the transience of my own acts, attitudes and (by extension) my sense of self.

\section{Non-self}

A logical extension to the concept of impermanence is that there is no fixed, permanent or essential self; an idea encapsulated in the Buddhist concept of 'non-self' (anattā). This concept suggests that the self has a fundamental plasticity and is therefore always in a state of flux. The impermanence of the self was at the centre of Jean-Paul Sartre's (1943) existential thought. Sixteen years after Heidegger's Being and Time, Sartre went as far as to suggest that human existence itself is defined by transience and uncertainty because it is predicated on a (misleadingly simple) dialectic. He 
postulates that humans are comprised of Being (in-itself): one's corporeal body and unchangeable past actions (facticity). He also suggests that the conscious mind is fundamentally nothingness (for-itself): the capacity to negate, transcend and project oneself onto future possibilities. $\mathrm{He}$ concludes that if human existence is the blend of Being (thesis) and non-Being (antithesis), the synthesis of these two ontological states is becoming. The authentic-self (for Sartre) is the self that recognises this perpetually fluid state of Being and (more importantly) engages in life's project in a manner that does not curtail one's becoming. The way one constitutes one's (authentic-)self is therefore fundamentally bound to one's conscious awareness of temporality and transience; the self is the culmination of one's past acts. As one continues to act, the self continues to evolve. The Buddhist and existential notions of ontological impermanence extend into and come to define their conceptions of selfhood. The authentic or 'mindful-self' (Xiao, et al., 2017) seeks to realise an uninterrupted state of transformation, as it is perpetually exposed to or engaged in transformative or transformational encounters and acts.

Performance artist Marina Abramović has repeatedly explored the curation of transformational experiences (Simões \& Maria, 2018). She often involves audience participants in her work, which she claims aims to facilitate transformation by breaking patterns of habit and confronting uncertainty (Stokić, 2010). Although Abramović is a meditator and has publicly expressed interest in Tibetan Buddhism on a number of occasions, Buddhist doctrine does not explicitly feature in work (Sleek, 2012). The importance of 'being present in both time and space [and a] focus on breath, stillness, and concentration' (Marina Abramović Institute, n.d.) however permeate not only her oeuvre, but also 
what she has come to term 'The Abramović Method'.

The Artist is Present (2010) was an example of Abramović's work which embodied these meditative attitudes and attempted to facilitate 'a transforming experience' which always came 'back to being present, breathing, maintaining eye contact' (Blancas, 2010) by creating an environment free of distractions 'allowing the "presence" of the artist to dominate' (Meledandri, 2010). Abramović sat in a chair, on one side of a small table in the Museum of Modern Art, New York, for eight hours a day, for three months. Participants were invited to sit in a chair on the opposite side and lock eyes with the performance artist.

By building upon Victor Turner's (1967) theory of liminal and 'liminoid' performative encounters, Richard Schechner (1988) proposed that performance and performative encounters are all in some way transformative. The transformative efficacy of performance events is not however limited to the transformation of an actor into a character; it extends into the transformation of the beliefs, opinions and habits of performers and audience members from when they enter the performance (liminal state) to when they leave and beyond. Jon McKenzie (2001) goes as far as to suggest that instances of cultural performance (e.g. theatre, rituals, performance art, etc.) can be primarily understood and evaluated in terms of their social efficacy. Or in other words, the quality and effectiveness of any performance is gauged by whether (and to what extent) audiences and participants are changed by the event. Performance events are a locus for change and none more so than those that invite audience members to participate. Claire Bishop defines participatory art as 'intentionally provocative and disruptive, challenging the status quo.' (2006, p. 14) Participants enter into performance situations where their 
self-perception and concept of self is thrown into sharp relief, often resulting in subtle modification, through to profound transformation. Similarly, Laurence J. Kirmayer suggests that western praxes of mindfulness meditation can fall anywhere on a spectrum that ranges from 'a dispassionate process of looking at the mind, which leads one eventually (inevitably?) to discover the way things really are' to 'a socially mediated enactment that aims to disrupt the structures of everyday life, opening a space in which new forms of identity and experience can emerge.' (2015, p. 461) In both participatory performance and mindfulness meditation, participants are given the tools to create space for themselves to interrogate their perception of the world and their (transitory) place in it.

The Artist is Present exposed participants to an idea (if not the idea) of non-self in two primary stages. Firstly,
Abramović placed the piece at the centre of a retrospective of work spanning her entire 40-year artistic career. The Artist is Present did not simply imply the presence of any person, or any artist for that matter; the encounter with Abramović was contingent on the accumulation of her previous work and her reputation as an artist who has mobilised presence and transformation as an aesthetic tool. Participants were not expecting to simply exchange eye contact with a person ${ }^{\mathrm{v}}$, but a 'persona.' (Taylor, 2010) By surrounding the encounter with her oeuvre, Abramović reinforced the expectations that participants had of her as an artist, as a personality and as a self. Participants brought this heightened set of rigid expectations to the encounter as they sat across from Abramović. The persona Abramović surrounded The Artist is Present with was a manifestation of what Sartre would call her 'facticity'. For Sartre, the self is the culmination of a series of 
acts that are only truly crystallised as a 'self' in one's memory and in the memory of others. By virtue of this crystallisation, the self is manifest in one's facticity (Beingin-itself). In The Artist is Present, participants sat across the artist with the full weight of expectation, anticipating an encounter with the facticity of the Marina Abramović.

This immediately seems at odds with both the Buddhist non-self and the existential authentic-self defined in its becoming. However, what participants found when they sat across from Abramović was not a larger-than-life, fearless and ground-breaking performance artist, rather they were faced with Abramović herself, immobile and unadorned, acting as just the mirror of their own self.' (Abramović, 2012) By surrounding the event with her facticity, but mobilising stillness and inactivity in the encounter, Abramović presented a vacuum of identity which invited participants to reflect, not on her identity, but on their own. Although not directly evoking the specifically Buddhist non-self, in this second stage, Abramović drew participants' attention to a distinct lack of self in their encounter with her by juxtaposing it with the heightened character of 'Marina Abramović', reinforced by her collected works and pervasive image (in marketing materials) surrounding the event (Fox, 2010). In the absence of the intense and overwhelming cultural celebrity personality, participants saw their own selves reflected back at them through Abramović's impassive gaze (Lader, 2014). By seeking interaction with Abramović they may have been in some way endeavouring to discover something about themselves.

In all engagement with the world Heidegger proposes a definite sense of 'mineness' that accompanies it by virtue of the finite embodied perspective from which the world is encountered. One has a 
unique perspective on the world, the other beings in it and how one (and others) act upon it. Each participant in The Artist is Present had their own unique encounter with Abramović because they were bringing with them their personal accumulated experience. Heidegger conceives of Dasein's selfhood in terms of one's relation to the world, others who inhabit it and one's worldly projects. Dasein is always in the world and therefore 'I experience myself immediately in what I do and in what I accomplish, in my concerns and in my relations with others.' (Escudero, 2014, p. 11) However, despite one's mineness, Heidegger 'rejects the idea of self as substantial core because it objectifies and deworlds human existence.' (2014, p. 10) In the moment of their encounter with the artist, participants were forced to confront their mineness and how that was inflecting their reaction to a distinct absence of self (embodied in Abramović the person, contrasted with
Abramović the persona).

Sartre similarly identifies the authentic-self as one which accepts the fundamental tension between facticity and transcendence. Like during meditation, one's conscious attention can rest on the present moment, but it will inevitably wander away to the past or future because 'consciousness's very nature is flight, constantly transcending the present towards its projects, intentions, motivations and desires.' (Sawyer, 2018, p. 72) One has facticity and a sense of mineness. The two are not however, the same thing necessarily. One also has a nihilating and transcendent consciousness, which is the ground of one's mineness. This dynamic synthesis of corporeal/social facticity and nihilating transcendence has the potential to form a flexible self, fully-equipped to face any and all of life's uncertainties.

Running concurrently to Abramović's performance was The Artist is Kinda Present (2010). The Artist is Kinda 
Present was a participatory piece by American artist, writer and researcher, An "An Xiao" Mina. Xiao describes the performance as 'a response piece to Abramović's The Artist Is Present, which was ongoing at MoMA at the time.' (2010) As such, the setup of the installation is an intentional mirroring of Abramović's installation: Xiao is sat before the participant, amongst a tangle of cables, and behind an assortment of devices and a sign that reads:

Sit down with the artist.

Find a comfortable position.

Be present with the artist in any of the following ways:

A text message to: [PHONE NUMBER]

A tweet to @anxiaostudio.

The artist will respond in kind.

When you have reached a satisfactory connection, or you simply grow bored, you may leave.

An Xiao, The Artist is Kinda Present

Xiao 'reimagined [Abramović's] piece as a Zen meditation exercise, with mats and cushions loaned by the New York Zen Center.' (Xiao, 2010) However, her association with meditative practice transcends the superficial appropriation of cushions and mats used in meditation. She has publicly referenced (Zen Buddhist teacher) Thich Nhat Hanh (2003) to support her thoughts on suffering and how it can act as a reminder of interconnectedness (2021). Like Abramović and Spencer, she has also ruminated on uncertainty and how the attitudes of mindfulness can provide a way of accepting doubt and the unknowable. Xiao cites Pema Chödrön's Comfortable with Uncertainty (2002), which she says 
has been 'a guiding handbook for me for years' (2020). Alongside impermanence and suffering, Chödrön refers to 'egolessness' as one of 'the facts of life'. It is 'a flexible identity. It manifests as inquisitiveness, as adaptability [...] It is our capacity to relax without knowing, not figuring everything out, with not being sure about who we are, or who anyone else is, either.' (2002, p. 45)

An Xiao attempted to evoke this egolessness and uncertainty by appropriating the anonymity of digital internet users: only communicating through the technologies of mediation afforded by the internet, social media and mobile phone communication. She also hid the most recognisable instrument of her embodied Look: her eyes (Abramović's primary instrument) by wearing sunglasses, and reduced any communication through body language by only moving very slightly to input data into a device to communicate digitally. This anonymous and adaptable non-self (Xiao presents to participants) is in direct contrast with the persona generated by Abramović's exhibition. Xiao was not surrounded by her past accomplishments. She did not sit amidst the accumulated acts that constituted her public and creative identity. Where there was a kind of 'egocentricity' (Marsh, 2015) surrounding Abramović's piece (which intensified the juxtaposition with the encounter itself), there was a distinct lack of signs and objects highlighting Xiao's identity or persona surrounding The Artist is Kinda Present. Even the title of Xiao's piece implies an ambiguity around both Xiao's status as an artist and the exhibition of herself during the encounter.

The digital-self An Xiao presented to participants was enigmatic, but adaptable and responsive. Participants may not have ever been entirely certain who it was they had sat across from and interacted with. At least, not in the way participants might 
have been certain they were sat across from Marina Abramović. What the participants of The Artist is Kinda Present found instead was an adaptable, egoless, anonymous, digitally mediated self they desired to connect with, despite the uncertainty surrounding their identity (Meledandri, 2010).

Both Abramović and Xiao were using the participatory mode of performance engagement to problematise the way we interact with others and the ways these altered interactions constitute the self. Abramović challenged the participants' expectations of her established cultural persona. Xiao 'frustrated any attempt to read her emotions' (Eler, 2013) or her identity by disconnecting her acts from her body through digital mediation.

\section{Equanimity \& Liminality}

During mindfulness meditation, if one has an understanding and appreciation of impermanence and the non-self, one is far better equipped to establish an attitude of equanimity. Likewise, if one can cultivate an attitude of equanimity, the fundamental transience of the world and one's self become more readily apparent. In many Buddhist traditions, the position of equanimity is considered both a perspective on one's own experience, unfastened from judgement (upekkha), and the capacity to be at the centre of this experience, but retain a balanced attitude (tatramajjhattata) (Fronsdal \& Pandita, 2005).

The understanding of equanimity as upekkha maps directly onto the phenomenological attitude established by Edmund Husserl (1900) and later developed by Heidegger (1927) and Sartre (1943). This attitude is defined by the 'bracketing' (temporary suspension) of both one's sense of selfhood (or 'Ego') and the critical appraisal that one would usually make of an encounter, founded in past 
experience and convention. By adopting this attitude, one is able to experience existence as it is in-itself. This was important for Heidegger and Sartre's ontological projects, but also for identifying the authentic mode of human existence, without the distorting strata of society, culture and history. Access to a perspective on one's own experience without these trappings directly influencing it could dictate how one should operate authentically as a being-in-the-world-withothers.

One could argue that by juxtaposing her exaggerated facticity (which surrounded and prefaced the event) with a relatively stoic presence (encountered by participants), Marina Abramović performed a bracketing of sorts. By nakedly holding each participant's gaze (with little else in the way of artistic paraphernalia), she stripped away all the history, narrative and significance of her artistic practice and cultural identity, putting it to one side (beyond the taped boundary of the performance space), so participants were not distracted by it and could immerse themselves in the encounter.

As well as a temporary suspension of judgement, equanimity as tatramajjhattata is reflected in the immersion in one's situation as a being-inthe-world-with-others, but more importantly the balance that is necessary to negotiate this situation authentically. Rather than pitting the individual (on the path to authenticity) against the Other/the herd/the They, existentialists like Heidegger and Sartre promote an attitude of balance, harmony and moderation. Existential authenticity is an act of resistance against the surrender of one's freedom and responsibility to others and the facticity that comes from being-in-the-world-with-others. However, the authentic-self cannot isolate itself from the Other (society) because human existence and authenticity is contingent upon its relationship with the 
Other as a 'being-in-the-world-with-others' (Heidegger, 1927). A balance between these extremes is required for an authentic realisation of one's Being. If one is to strive for authenticity ${ }^{\mathrm{vi}}$, one must establish and maintain a liminal state of Being which sits 'betwixt and between' (Turner, 1967, p. 93) more everyday modes of inauthenticity. The authentic-self is not only in a perpetually fluid state between the concrete parameters of birth and death, but balances the urges from within with the pressures and influences from without.

Charlotte Spencer's use of wireless headphones to feed participants instructions was a means to not only practically deliver narrative, but to also manage a fine balance between isolation and connection (Klich, 2017). Each participant's experience was unique by virtue of their distinct spatio-temporal pointof-view (their mineness) of the waste lands, which could not be replicated by any other participant. But this exclusivity was augmented because each participant was being fed one of five different verbal narratives and associated directives. Each participant (through a combination of directed action and free choice) was on their own little adventure. However, these adventures were often punctuated by the appearance of other participants on their own unique journeys. If participants were invited to use nearby rubbish to build a wall, they would simultaneously be immersed in their own project, but also encounter other participants adding to the same wall with their own bits of rubbish found about the waste land. The bracketing of Abramović's facticity beyond the taped performance area and the limbo between connection and isolation between Spencer's participants navigating the waste lands are not only both instances of equanimity, but liminality.

More generally, upon accepting the invitation to participate in a performance event, one enters a liminal state: neither 
spectator, nor performer. This state of liminality is even more profound than the one Lalioti (2019) proposes nonparticipating audiences enter into, and the potential for transformation is even greater. As a participant, one's beliefs and behaviors are open to questioning, manipulation and transformation. Participation opens up the possibility for participants to forge a very public identity that may only last the length of the performance. One could choose to reinforce some pre-existing aspects of one's identity, dispense with others, or create an entirely new persona befitting the context of the performance, all whilst in possession of the implicit knowledge that whatever one does as a participant is temporary, only lasting as long as the performance (if one so wishes). The performance is transitory and so is the self that participates. The participant is given the opportunity and space to inhabit the non-self, one that is constantly in flux and resisting an essential identity.

All three of the previously discussed performances provided participants with a physical and psychological step back and away from their situations and from their everyday lives and their established everyday selves. I believe these evocations of equanimity and liminality are integral in how these artists generated an aura of mindfulness in their performances. For example, Spencer invited participants into spaces that were the definition of liminality: the overgrown remains of demolished buildings awaiting purchase and development. Participants and performers were surrounded by the busy urban landscape, which carried on as normal beyond the boundaries of the waste land; they were caught in a bubble of quietude and untapped potential. Upon entering one of these overgrown and unused spaces, surrounded by bustling urban life, I was personally struck with the profound feeling of having breached a 
threshold and even of having discovered a hidden pocket-dimension, in the otherwise regular cityscape. The world was still present beyond the waste land's boundary fence, but participants were insulated from it, sequestered from the stress and/or excitement of the clamouring hoi polloi outside. This breach, and the liminality of the waste land, was given a heightened significance by the 'theatrical frame' (Bennett, 1997) established by the ritual of handing over one's ticket, being granted entrance to the performance space, handed programme materials, and being fitted with wireless headphones.

A similar (if not amplified) ritual preceded The Artist is Present. Abramović drew more than 850,000 pilgrims to MoMA for the 700-hour-long performance and many 'queued all night for a one-to-one audience with [her].' (O'Hagan, 2010) Participant, Rebecca Taylor, described her experience of waiting to sit across from Abramović:
More than three hours from when I entered the succession l've seen only six people participate in the performance and more than thirty leave the line in frustration. The nameless, faceless strangers I queued with hours ago are now friends.

The extended queueing time, the heightened anticipation it induced and the media furore surrounding the event, however, was noticeably juxtaposed with the serenity and stoicism of Abramović herself. Only a tape-mark on the ground and a square of light seperated those queuing from those participating. Abramović curated a pocket of space which participants could use to hold the rest of the world at arm's-length. The queues remained, the museum and the 
world beyond continued, but in the seat across from Abramović, participants could temporarily suspend their situation, find themselves reflected in her blank gaze, and exploit the space offered to transform.

Queues to sit across from An Xiao did not extend out the door, nor the building. Participants were not whipped up into a frenzy by the presence of her luminary persona and their time with the artist did not demand every last drop of their razor-sharp attention. Participants did not bring with them the same expectations when interacting with Xiao as they did Abramović. However, Xiao was still able to induce a liminal state in her interactions with participants and she did so without establishing a definite physical threshold.

Spencer sought to stress the incongruity of the serene waste land as it was juxtaposed with the bustling metropolis, separated only by capitalist utility (and a fence). Abramović carved out a space in the atrium of MoMA to be 'the eye of the tornado' (Abramović, 2011), where participants could not help but notice the stark contrast between the two sides of the tape-mark separating the queue and the performance space. Xiao did not make such an explicitly corporeal distinction. Instead, the liminality she created resided in the space between the physical and the digital. Rather than interact directly with the participant, or even make direct eye-contact, the artist kept herself physically and socially separate from the participant. However, she extended a significant connection through digital technology. The tension between distancing mediation and intimacy is the foundation of the liminal state Xiao cultivated in The Artist is Kinda Present. It is a tension people around the globe are feeling more so than ever right now as they are compelled to be physically isolated, but digitally connected.

\section{Conclusion}


I am writing this during the Covid-19 pandemic and, like when I was approaching the end of my doctoral studies, I am racked with uncertainty, like many others in this unprecedented time (Finn, et al., 2020). Uncertainty is a fundamental part of modern life, however never has it been more pronounced, nor has it infiltrated the lives of so many than during this global crisis. Concurrently, there has been a significant swell of interest in meditative and mindfulness praxes since the Covid-19 pandemic hit (Perez, 2020) and a general acknowledgment that mindfulness has 'crept into mainstream culture.' (Behan, 2020, p. 256) When prominent figures in the contemporary mindfulness movement, such as Pema Chödrön, invite us to get 'comfortable with uncertainty' (2002), it starts to become clearer why there has been such a resurgence.

Even before the pandemic, uncertainty was a mounting issue (Jeffries,
2016) and mindfulness was being held up as a means to combat it. An estimated 200-500 million people (and counting) worldwide are engaged in some form of meditative practice (The Good Body, 2019). Mindfulness has secured a foothold in mainstream culture thanks to celebrity endorsement, the culture of self-help, technocapitalism (Purser, 2019) and the aforementioned ubiquitous uncertainty felt around the globe. The central way one can mobilise mindfulness to mitigate feelings of uncertainty is to cultivate an understanding and acceptance of existential truths like the impermanence of all things, including the self. If nothing lasts, how can I know what will persist from one year, day or moment to the next? If impermanence extends to all things, who will I be tomorrow or next year and how will future-me react to unknown future-situations?

Contemporary participatory performances, like The Artist is Present, The Artist is Kinda Present and Is this a Waste 
Land? seem primarily occupied with uncertainty. By engaging with ambiguity and doubt, they have evoked ideas like impermanence, the non-self and drawn upon attitudes of equanimity to explore it. It is unclear whether this has been done intentionally. In all cases, the artists/performers do not explicitly subscribe to Buddhist doctrine, yet they admit to at least a general interest in meditative philosophies and have in some way channelled these concepts through their work. Even without direct engagement with mindfulness, if one considers the proliferation of mindfulness in mainstream culture and the positive correlation between artistically minded people and the likelihood of exploring meditative practices (NERIS Analytics Limited, 2016), mindfulness could be considered a broadly influential factor in the making of their participatory work.

Both impermanence and the lack of any core essential self, are both driving forces behind the uncertainty we face in our everyday contemporary lives and are reflected in these pieces. However, rather than challenge uncertainty, try to bend it to their will or present it to participants as a problem requiring a solution, Spencer, Abramović and Xiao invite participants to explore uncertainty. Uncertainty around where they are, who they are and who other people are (or seem to be). All three performances created liminal environments amid (but sequestered from) normalcy, within which participants could nurture attitudes of equanimity in the face of uncertainty. Strategies to do so ranged from: staging the performance at an empty, forgotten site situated amidst urban clamour, curating a pseudo-sacred opening surrounded by hysteria, or mediating the encounter with the artist through digital technology. They did so to create a space for raising awareness and facilitating transformation. These invitations to participate were not aimed at 
eradicating participants' uncertainty, rather they engaged in a 'bringing-forth' (Heidegger, 1954) of uncertainty. By evoking the transience of encounters and objects, throwing the fluidity of identity into sharp relief, and providing a safe, liminal space to explore them in, these artists facilitated a gradual process of revealing uncertainty and becoming as fundamental and authentic to participants' existence. The authentic-self is uncertain. These pieces do not help participants feel less uncertain about their situation, their relationships with others, their worries about the past and the future, and who they (and others) perceive themselves to be. Instead, they affirm uncertainty, flux, becoming, transformation and liminality.

\section{Notes}

i The third being suffering (duhkha).

ii The other three being loving-kindness (metta), compassion (karuna) and empathetic joy (mudita).

iii Other notable examples of participatory performance that promote a liminal attitude towards one's constitution of the self (and its relationship with others) include Ontroerend Goed's Personal Trilogy: The Smile Off Your Face (2004), Internal (2007) and A Game of You (2009), Hannah Jane Walker \& Chris Thorpe's I Wish I Was Lonely (2013), Gob Squad's Western Society (2013) and Blast Theory's Karen (2015), to name but a few.

iv However, this attitude towards perpetual change and fundamental impermanence is extended within Buddhist doctrine to include concepts of endless cyclical becoming and rebirth (saṃsāra) (Gyatso \& Chodron, 2019). This implies the 
transferral of kamma, as opposed to the existence and transmigration of an immutable soul (Neufeldt, 1986). There is no precedent for such a transferral in existential thought after Kierkegaard. The existential focus on the individual is perhaps a symptom of its myopic humanism.

${ }^{\vee}$ Although, poet Hannah Jane Walker and Dramaturg Chris Thorpe engineer a performance situation in their piece entitled I Wish I Was Lonely (2013) wherein participants are invited to spend two minutes sharing eye-contact with another participant.

vi Both Heidegger and Sartre were sceptical about any form of sustained or stable authenticity (Golomb, 1995) and rather theorised more concretely about the prevalence of inauthenticity and the (more likely, albeit slim) possibility of one performing anomalistic authentic acts.

\section{References}

Abramović, M., 2010. The Artist is Present. New York: s.n.

Abramović, M., 2011. The Artist is Present [Interview] (September 2011).

Behan, C., 2020. The benefits of meditation and mindfulness practices during times of crisis such as COVID-19. Irish Journal of Psychological Medicine, 37(4), pp. 256-258.

Bennett, S., 1997. Theatre Audiences: A Theory of Production and Reception. 2nd Edition ed. London: Routledge.

Bishop, C., 2006. The Social Turn:

Collaboration and its Discontents. Artforum International Magazine, February.pp. 178183.

Blancas, P., 2010. The Artist is Present. [Online]

Available at:

https://www.moma.org/learn/moma learnin g/marina-abramovic-marina-abramovicthe-artist-is-present-2010/ [Accessed 28 May 2020].

Chödrön, P., 2002. Comfortable with Uncertainty: 108 Teachings on Cultivating Fearlessness and Compassion. Boston: SHAMBHALA PUBLICATIONS, INC..

Crawford, J.-L., 2016. Practice and Projects. [Online]

Available at:

https://charlottespencerprojects.org/catego ry/is-this-a-waste-land/writings/page/2/ [Accessed 16 January 2021].

Crowell, S., 2020. Existentialism. [Online] Available at:

https://plato.stanford.edu/archives/sum202 0/entries/existentialism/

[Accessed 15 November 2020].

Eler, A., 2013. The Artist Is Not Present But the Brand Sure Is. [Online] Available at: 
https://hyperallergic.com/75766/the-artistis-not-present-but-the-brand-sure-is/ [Accessed 30 January 2021].

Escudero, J. A., 2014. Heidegger on Selfhood. American International Journal of Contemporary Research, 4(2), pp. 6-17.

Finn, P., Mysore, M. \& Usher, O., 2020. When nothing is normal: Managing in extreme uncertainty. [Online]

Available at:

https://www.mckinsey.com/businessfunctions/risk/our-insights/when-nothing-isnormal-managing-in-extreme-uncertainty\# [Accessed 20 February 2021].

Fox, D., 2010. Ten Notes on Marina Abramović's 'The Artist is Present'. [Online] Available at:

https://www.frieze.com/article/ten-notesmarina-abramovićs-artist-present [Accessed 29 January 2021].

Fronsdal, G. \& Pandita, S. U., 2005. A Perfect Balance. [Online] Available at: A Perfect Balance [Accessed 17 May 2020].

Hanh, T. N., 2003. Mindfulness, Suffering, and Engaged Buddhism [Interview] (7 October 2003).

Heidegger, M., 1927. Being and Time. London: Blackwell Books.

Heidegger, M., 1954. The Question Concerning Technology. In: New York: Garland Publishing.

Husserl, E., 1900. Logical Investigations. London: Routledge.

Irvine, L., 2017. Review: Charlotte Spencer - Is This A Waste Land?. [Online] Available at:

https://thetempohouse.wordpress.com/201 7/05/16/review-charlotte-spencer-is-this-awaste-land/

[Accessed 30 July 2018].

Jeffries, S., 2016. Welcome to the new age of uncertainty. The Guardian, 26 July.
Kershaw, B., 2011. Research Methods in Theatre and Performance. Edinburgh: Edinburgh University Press.

Kirmayer, L. J., 2015. Mindfulness in cultural context. Transcultural Psychiatry, 52(4), pp. 447-469.

Klich, R., 2017. Amplifying Sensory

Spaces: The Inand Out-Puts of

Headphone Theatre. Contemporary

Theatre Review, 27(3), pp. 366-378.

Lader, R., 2014. The Artist Is Present and the Emotions Are Real: Time, Vulnerability, and Gender in Marina Abramovic's Performance Art. WR: Journal of the CAS Writing Program, Issue 6, pp. 26-34.

Lalioti, V., 2019. Performance as Shared Mindfulness. The Journal of Performance and Mindfulness, 2(2).

MacQuarrie, J., 1972. Existentialism. New York: Penguin.

Marina Abramović Institute, n.d. The Abramović Method. [Online]

Available at: https://mai.art/abramovicmethod

[Accessed 23 January 2021].

Marsh, A., 2015. Marina Abramović:

Mindful immateriality. [Online]

Available at:

https://www.artlink.com.au/articles/4363/m arina-abramoviC487-mindful-immateriality/ [Accessed 24 November 2020].

McKenzie, J., 2001. Perform or Else: From Discipline to Performance. London:

Routledge.

Meledandri, N., 2010. The Artist is Kinda Present. [Online]

Available at:

http://morerandomthoughts.tumblr.com/pos t/607256974/the-artist-is-kinda-present [Accessed 14 April 2018].

Mina, A. X., 2020. On Uncertainty. [Online] Available at:

https://anxiaomina.medium.com/onuncertainty-5d0a0156209f

[Accessed 30 January 2021]. 
Mina, A. X., 2021. A Meditation for Times of Heartbreak. [Online]

Available at: https://medium.com/curious/ameditation-for-times-of-heartbreak-

c25edea1349a

[Accessed 2021 January 2021].

NERIS Analytics Limited, 2016. Meditation: Which Personality Types Are More Likely to Try It?. [Online]

Available at:

https://www.16personalities.com/articles/tr ying-meditation-which-personality-typesare-more-likely-to

[Accessed 20 February 2021].

O'Hagan, S., 2010. Interview: Marina

Abramović. [Online]

Available at:

https://www.theguardian.com/artanddesign /2010/oct/03/interview-marina-abramovicperformance-artist

[Accessed 20 November 2020].

Perez, S., 2020. Meditation and

mindfulness apps continue their surge

amid pandemic. [Online]

Available at:

https://techcrunch.com/2020/05/28/meditati on-and-mindfulness-apps-continue-their-

surge-amid-

pandemic/?guccounter $=1 \&$ guce referrer $=a$

HR0cHM6Ly93d3cuZ29vZ2xILmNvbS8\&g

uce referrer sig=AQAAALyMBtNIZu6BTtX

nXiTXPbr78XQfu2Nxuz8 NGkNtGUa_9s7

WSCbpXDMAzoQgXY41Bj5z6Tu

[Accessed 20 February 2021].

Purser, R. E., 2019. McMindfulness: How Mindfulness Became the New Capitalist Spirituality. London: Repeater.

Sartre, J.-P., 1943. Being and Nothingness: An Essay on

Phenomenological Ontology. Routledge

Classics Edition ed. London: Routledge.

Sawyer, D., 2018. Mindfulness Meditation: A Sartrean Analysis. Sartre Studies International, 24(2), pp. 66-83.

Schechner, R., 1988. Performance Theory. 2nd ed. New York: Routledge.
Simões, L. \& Maria, P. C., 2018. The Performance Art of Marina Abramovic as a Transformational Experience. Psychology, Volume 9, pp. 1329-1339.

Sleek, 2012. An Interview with Marina Abramovic, the Mistress of Metaphysics.

[Online]

Available at: https://www.sleek-

mag.com/article/the-mistress-ofmetaphysics/

[Accessed 23 January 2021].

Spencer, C., 2017. Is This a Waste Land?. Corby: Charlotte Spencer Projects.

Stokić, J., 2010. The Art of Marina Abramović: Leaving the Balkans, Entering the Other Side. In: M. Christian, ed. The Artistis Present. New York: The Museum of Modern Art, pp. 22-27.

Taylor, R., 2010. Marina Abramović, The Artist is Present. [Online]

Available at:

https://www.khanacademy.org/humanities/ global-culture/conceptual-

performance/a/marina-abramovi-the-artistis-present

[Accessed 13 February 2019].

The Good Body, 2019. Meditation

Statistics. [Online]

Available at:

https://www.thegoodbody.com/meditationstatistics/

[Accessed 15 May 2020].

Turner, V., 1967. The Forest of Symbols: Aspects of Ndembu Ritual. London:

Cornell University Press.

Wheeler, M., 2020. Martin Heidegger.

[Online]

Available at:

https://plato.stanford.edu/entries/heidegger I

[Accessed 15 January 2021].

Xiao, A., 2010. The Artist is Kinda Present. New York: s.n.

Xiao, A., 2010. The Artist is Kinda Present. [Online] 
Available at:

http://www.anxiaostudio.com/art/artistiskin dapresent.html

[Accessed 14 April 2018].

Xiao, Q., Yue, C., He, W. \& Yu, J.-y., 2017.

The Mindful Self: A Mindfulness-

Enlightened Self-view. Frontiers in

Psychology, Volume 8. 